\title{
PROGRESS MONITORING OF MASONRY WORK VIA RESOURCE TRACKING USING SENSOR-BASED TECHNOLOGIES
}

\author{
Gursans Guven ${ }^{1}$ and Esin Ergen ${ }^{2}$
}

\begin{abstract}
Current manual methods used for construction activity monitoring is costly and error-prone, and they lead to inefficient decision making, delays and cost overruns. The aim of this study that is explained in this paper is to automatically monitor construction activities by tracking major resources by fusing sensor-based technologies. This study specifically focuses on double-shift construction sites and proposes an approach that can be used both during the day and night shifts. A proofof-concept prototype was developed and implemented at a construction site for monitoring the progress of masonry work. The resources that were tracked were the equipment used in performing the activity (i.e., tower crane and construction hoist) and the bulk material (i.e., reusable concrete masonry block pallets). This paper provides the requirements identified for utilizing the technologies (i.e., position and load sensors on tower crane and RFID system on hoist) to track construction equipment and bulk material in monitoring the masonry work progress. The prototype development and the test set-up are described. Finally, the preliminary results achieved during the implementation of the prototype and the challenges observed are presented.
\end{abstract}

Keywords: Automated progress monitoring, equipment tracking, sensor-based technologies.

\section{INTRODUCTION}

Effectively monitoring the progress of construction projects is crucial for better allocation and control of construction resources and for avoiding delays and cost overruns. However, the current methods that are used for monitoring construction projects are not effective. Project control and monitoring at sites is performed based on the information that is collected from field through visual investigation based on personal experience. The collected information is mostly missing and/or incorrect, and takes considerable amount of time to collect (Akinci et al., 2006; Golparvar-Fard et al., 2012).

To address this problem, previous studies developed automated progress monitoring solutions for construction sites using several automated field data capture technologies (e.g., Radio Frequency Identification (RFID), Global Positioning System (GPS), UltraWideband (UWB), laser scanner, video camera). The most recent studies that focus on progress monitoring use vision-based techniques (e.g., laser scanning, video, photography) to capture the as-built condition of building elements to perform model-based progress monitoring (Brilakis et al., 2011; Heydarian et al., 2012; Golparvar-Fard et al., 2012; Turkan et al., 2012; Cheng and Teizer 2013), and to track the equipment used in

1 Assistant Professor, Faculty of Engineering, Civil Engineering Department, Ozyegin University, Istanbul, Turkey, gursans.guven@ozyegin.edu.tr

2 Associate Professor, Faculty of Civil Engineering, Civil Engineering Department, Istanbul Technical University, Istanbul, Turkey, esin.ergen@itu.edu.tr 
earthmoving and excavation activities (Montaser and Moselhi, 2012; Pradhananga and Teizer, 2013; Heydarian et al., 2012; Pradhan and Akinci, 2012; Rezazadeh et al., 2013; Vasenev et al., 2014). Studies on equipment tracking during construction of buildings were limited to tracking one particular equipment type or resource to monitor the progress (Sacks et al., 2005; Weerasinghe and Ruwanpura 2009; Gong and Caldas, 2010; Yang et al., 2012; Costin et al., 2012). The limitation of these studies is that they can only be used to monitor the daytime work, since vision-based technologies do not work well at night.

Previous studies that utilize non-vision techniques to track construction resources, were mostly limited to fusing the ID information (e.g., from RFID) with location information (e.g., from GPS) (Ergen et al., 2007; El-Omari and Moselhi, 2011; Shahi et al., 2014). The overall objective of the study explained in this paper is to determine the progress at site by fusing the location and trajectory information of major resources (e.g., equipment and bulk materials) that are utilized in construction activities via sensor-based technologies. The focus is double shift construction sites; therefore, the approach is aimed to work at both night and day conditions. This paper presents the requirements that were identified for utilizing the technologies (i.e., position and load sensors on tower crane and RFID system on hoist) for tracking construction equipment and bulk material to monitor the masonry work progress at double shift construction sites. In addition to that, the test set-up developed for the prototype is presented, and both the preliminary results and the challenges observed during the implementation of the prototype are given.

\section{VISION}

Figure 1 illustrates the vision of the study. In this vision, major construction equipment and bulk materials, which are utilized to perform activities in building projects, are tracked at different stages of a construction.

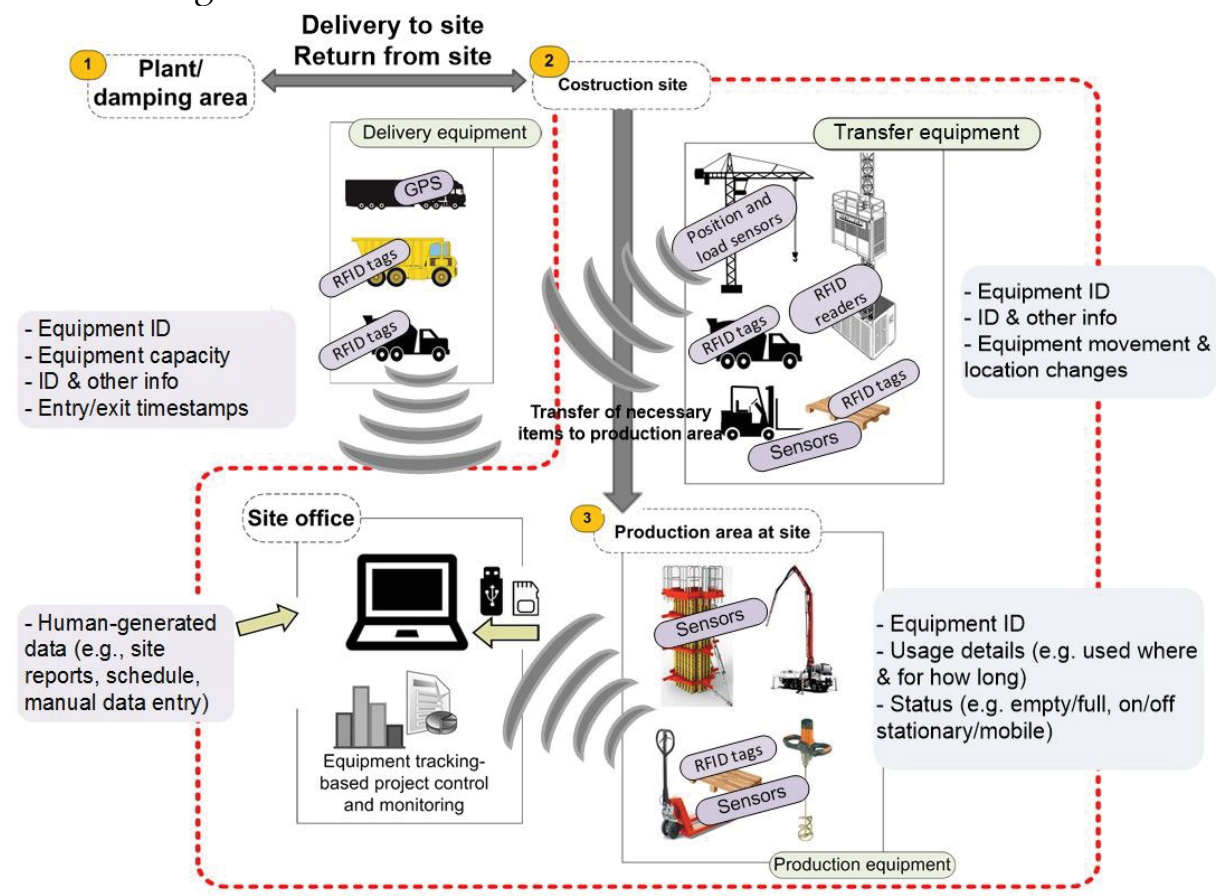

Figure 1: Vision of the study

For data collection, sensors that are either embedded in the equipment or installed will be utilized. Examples of the collected data are the trajectory of the equipment, when and 
where the equipment and/or the bulk material are used. In addition, human-generated data (e.g., site reports) are used in the approach to support sensor based data to (1) determine the different activity steps (e.g., storage, installation) that are completed, and (2) extract activity-related information (i.e., duration) for assessing activity progress and performance. Activity progress is measured in terms of completion percentage of an activity based on physical completion or material usage. On the other hand, activity performance is determined by comparing the planned and actual activity parameters (i.e., start and end dates, quantity of work).

\section{Proposed Monitoring Method}

The scope of the study explained in this paper was limited to resource tracking at construction sites (shown with a dashed line in Figure 1). A prototype was developed and implemented at a high-rise residential project site for monitoring masonry work by tracking (1) major construction equipment (i.e., tower crane and hoist), and (2) bulk materials that were used (i.e., concrete masonry block pallets). In the prototype, a rulebased reasoning method was developed to fuse the sensor-based data and the humangenerated data. The developed data fusion approach considers (1) the method of activity and (2) the precedence relation of the activity steps.

First, site observations were performed to identify the current method of masonry work, including the equipment usage and the precedence relation of the steps of the masonry work. Two activity steps were identified: (1) transfer of concrete masonry block pallets from the laydown area to the installation area, and (2) installation of concrete masonry blocks and clean up of floor (Figure $2 \mathrm{a}$ and $2 \mathrm{~b}$ ). The developed approach first identifies the completion of each of the activity step using the related sensor data and human-generated data (i.e., start and end dates of each activity step and the amount of work performed in each step). Then, the information obtained in each step is integrated to assess the overall activity progress.

The prototype was designed to work under the current site conditions, considering the observed method of masonry work (Figure 2). The tracked resources were the tower crane, construction hoist, and the reusable concrete masonry block pallets. Two criteria used in selecting sensor-based technologies were cost-efficiency, minimal interference with the existing work flows and ability to work both day and night. In addition to the RFID system deployed in the construction hoist, the existing embedded sensing technologies on the tower crane were also integrated in the prototype.

In the first step, tower crane transfers the pallets that carry concrete masonry blocks from the laydown area to a building floor, where installation will be performed (Figure 2a). The position sensors and load sensors that are embedded in tower crane's anti-collision system are used for tracking this activity step. The sensor data is used to (1) track the trajectory of the tower crane to determine completion of masonry block transfer from the laydown area to the installation area at the building, and (2) determine the weight of the carried loads to quantify the masonry blocks transferred to the installation area.

In the second step, as the concrete masonry blocks are being installed, the floor is cleaned up on a regular basis by removing the empty material pallets from the corresponding floor via the hoist (Figure 2b). To identify the start date of the masonry installation step, the site reports (i.e., human-generated data) are utilized. Concrete masonry block material pallets were tagged with RFID tags and an RFID system was deployed on the construction hoist (1) to identify the floor at which the tagged material pallets are loaded to the hoist for being removed from the floor during each clean up 
operation, and (2) to detect the number of pallets that are removed. The number of removed masonry block pallets are used to calculate the quantity of concrete masonry block utilized at the floor. The end of installation step is also identified from the information obtained from the site reports.

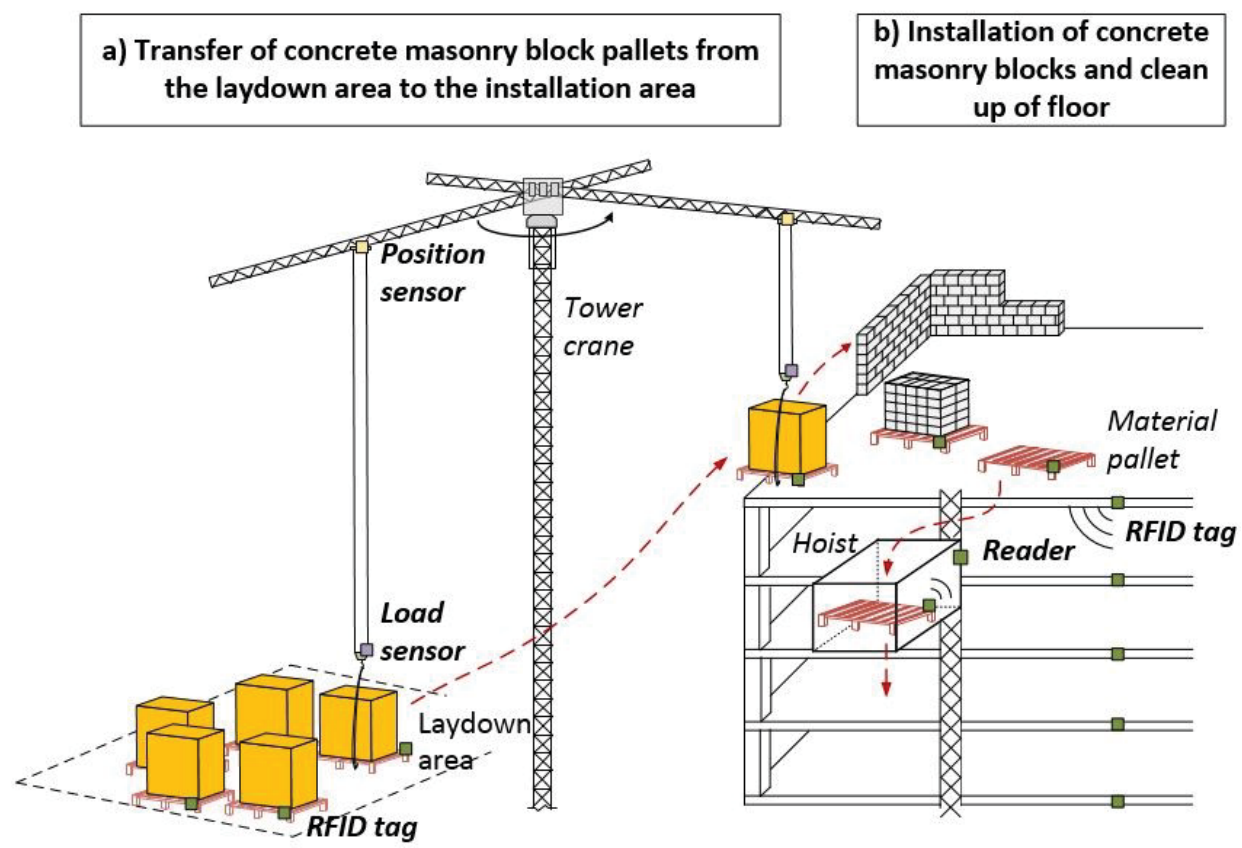

Figure 2: Current method of masonry work and components of the prototype

\section{REQUIREMENTS}

Site observations and initial tests were conducted to identify the requirements for tracking the masonry work using the selected type of technologies (i.e., RFID, position and load sensors). Based on the identified requirements, the technologies were selected and installed as part of the prototype. This section provides details on the implementation of the prototype along with the challenges observed while tracking the construction equipment and bulk material using sensor-based technologies for progress monitoring.

- RFID system on hoist:

RFID technology was selected as it is cost-effective, does not require line-of-sight, is not effected by different lighting conditions, has long reading range, requires minimal manual input, and is physically durable. The RFID system was configured for tracking the hoist movements and the tagged material pallets carried with the hoist. It consists of one RFID reader (Motorola FX740), two antennas (MTI MT-242040), a notebook, a 12V 40Ah additional power supply and a modem used as a bridge in between the computer and the reader. The operating frequency of the reader is $902 \mathrm{MHz} 928 \mathrm{MHz}, 865 \mathrm{MHz} 868 \mathrm{MHz}$, included in the UHF frequency. An "active reader - passive tag" system was designed and installed on the hoist that serves the test building (Figure 3).

An antenna was placed outside of the hoist facing towards the building to track the floor at which the hoist stops for loading and/or unloading (Figure 3b). The other antenna was placed inside the cabin on the ceiling to detect the wall block material pallets that are carried (Figure 3a). Since the hoist is used for carrying large items, the RFID reader and other components (i.e., notebook, power supply and modem) was placed outside on top of the hoist to avoid displacement and/or malfunctioning by accident (Figure 3b and 3c). A 
case was used for protection of the components that are on the outside of the hoist, and the overall set-up was able to withstand harsh conditions such as impact (e.g., object falling from upper floors), rain and cold weather.

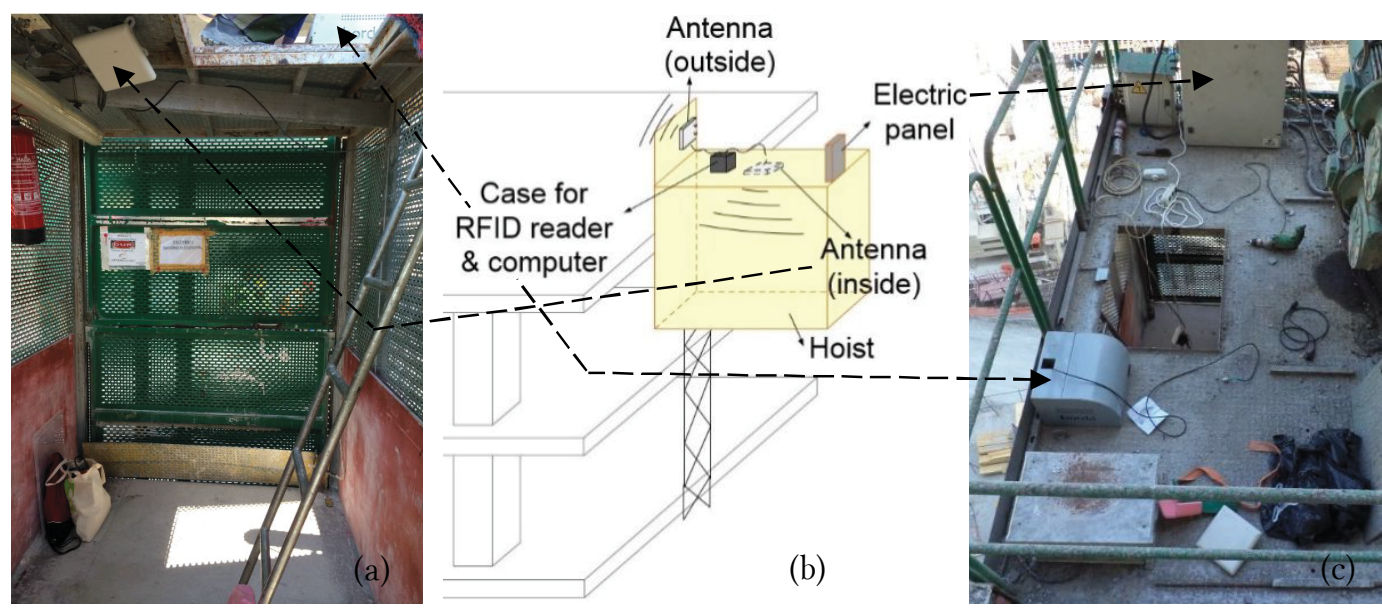

Figure 3: (a) Inside the hoist, (b) illustration of the RFID system on hoist, and (c) top view of the hoist

The reading ranges of both antennas were determined for automatic identification of tagged items. The reading range requirement for the antenna that was placed outside was based on the distance (i.e., $20 \mathrm{~cm}$ ) between the hoist and the building façade. The longest distance diagonally measured inside the hoist is approximately $4 \mathrm{~m}$., which was set as the reading range of the second antenna. Although the components of the RFID system installed on the hoist can obtain power from the hoist's electric panel (Figure 3b and 3c); additional battery was needed to power them for data collection in case of a power outage.
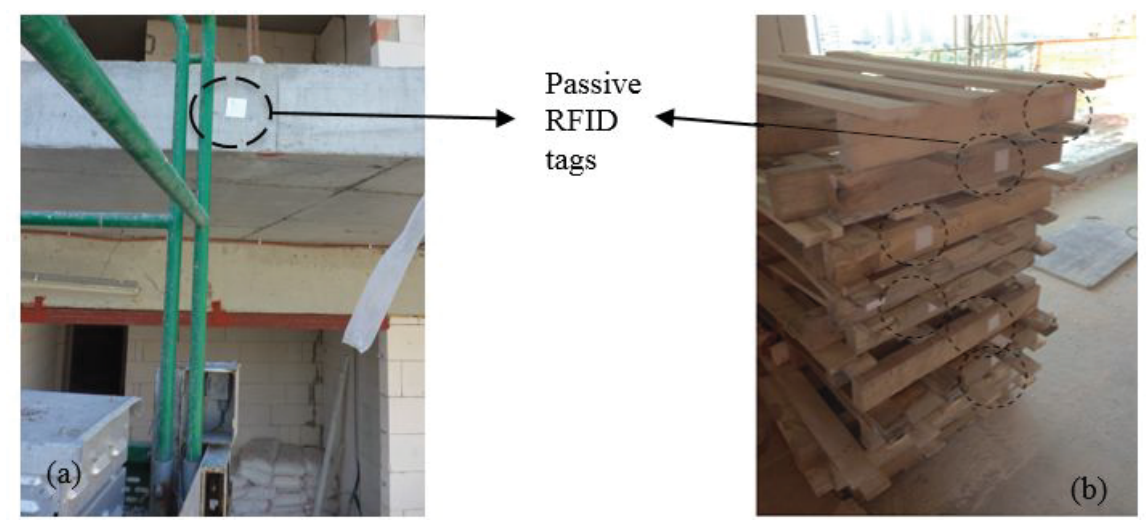

Figure 4: Passive RFID tags on (a) building floors, and (b) masonry block pallets

Another component of the RFID system were the passive tags on floors and masonry block pallets that are to be tracked. Masonry block pallets were tracked for identifying the size and amount of wall blocks used for masonry work at a particular floor. Figure 4 shows the passive RFID tags attached to each building floor and to the masonry block pallets. If tags came off and fell out due to harsh conditions at construction site (e.g., moisture), double-sided tape was used to attach the tags to material pallets.

- Tower crane position sensors and load sensor: 
To track the trajectory of the tower crane and the loads it carries, some of the embedded anti-collision system sensors on the crane were used. Figure 5 illustrates the anti-collision system, which consists of several sensors (e.g., angular position sensor, trolley position sensor, wind sensor, clinometer) and a central unit that includes a data logger. The system is primarily deployed on tower cranes for remote monitoring of the crane movements and for automatically avoiding collision of cranes that are in close proximity to each other. Real-time data is collected from sensors and the sensor data is stored in an SD card inside the data logger every 2 seconds. In the prototype, data collected by three sensors were utilized: trolley position sensor, angular position sensor and the load sensor.

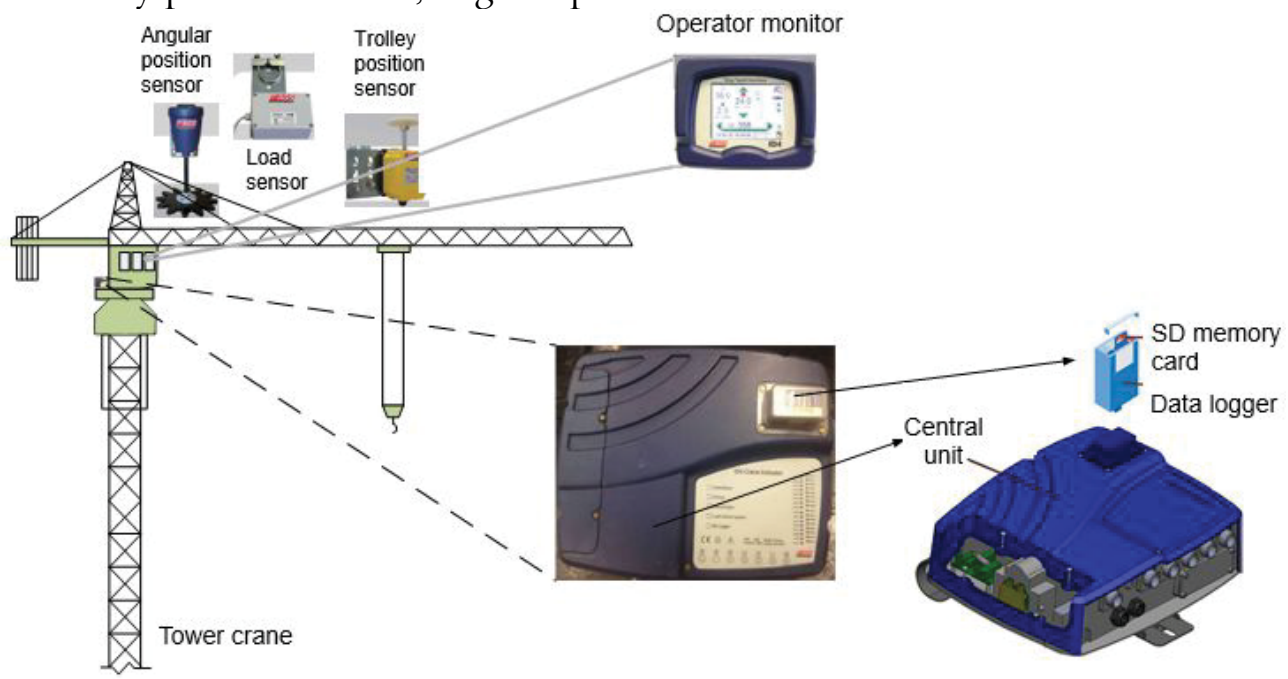

Figure 5: Components of the embedded anti-collision system on the tower crane

During the tests, it was determined that the weight that is measured at the beginning and end of a load lifting activity is not the same as the weight measured in between. The acceleration of the crane's hook during lifting and lowering causes the load sensors to detect different weights at different stages of a single load lifting/lowering activity. Also, the wind and other weather factors, and the friction affect the load measurements in the course of a load lifting activity. To overcome this issue, some rules need to be defined for analysing the sensor data to identify load lifting activities, and determine the load's weight.

\section{DATA FUSION AND PRELIMINARY RESULTS}

The developed data fusion approach identifies the amount of work completed in each activity step by using rule-based algorithms (Figure 6). Each load transfer activity of the crane is identified by fusing load and position sensor data. The crane boom and trolley locations both at the beginning and end of each load transfer activity are matched with the site layout information, and the load transfers that are related to the masonry work are identified (i.e., transfers that begin at the laydown area and end at the installation area on building). Load carried in each transfer are calculated and transformed into the amount of transferred masonry block pallets. Daily site reports are used to identify masonry block installation activity that is started at a particular floor. RFID readings on the hoist are checked to identify the pallets removed from the floor with each clean up to calculate the amount of masonry blocks utilized at the floor. The final step is to calculate the progress in terms of material usage. The ratio of number of masonry block pallets transferred to the installation area to that of utilized at the floor reports the masonry work progress at that 
floor. Preliminary results were successful as the masonry work progress was determined with $96 \%$ accuracy at a floor of the test building. Also, the performance of the activity is identified by comparing the planned dates with the actual dates.

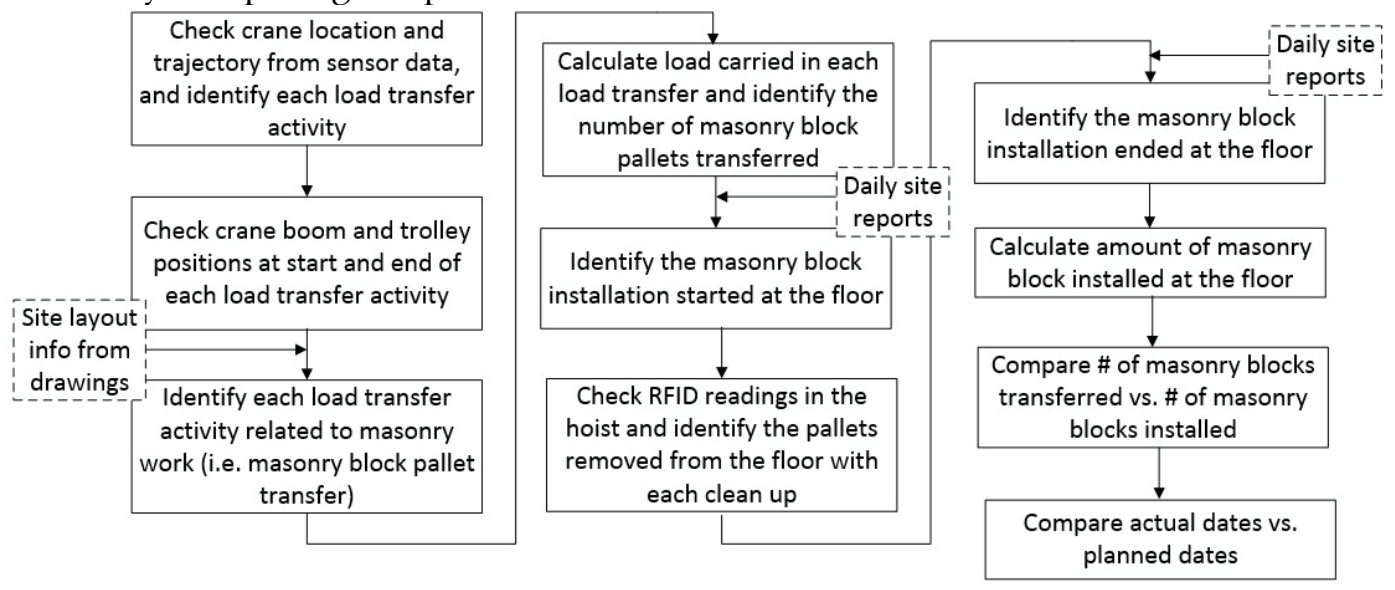

Figure 6: Data fusion approach for identifying masonry work progress at a floor

\section{CONCLUSIONS}

This paper is part of a vision that aims to track major construction equipment and some bulk material with sensor-based technologies at construction sites for activity progress monitoring. The main focus is on double-shift construction sites, and therefore, a costeffective approach that can be used both during the day and night shifts, and has minimal interference with the existing work flows is proposed. This approach fuses sensor data that is supported with human-generated data for identifying the method of activity and the precedence relation of the activity steps that are performed for completing an activity. An overview of the challenges in tracking the equipment and the bulk material at reinforcement concrete building projects was presented. The identified challenges were mostly related to the harsh site conditions (e.g., open-air, weather). Also, the geometry and dimensions of the construction equipment and their main utilization purpose limited the positioning of sensors. The study yielded successful results during the site tests. The next steps of the study include completion of the field tests and showing the feasibility of the approach on a broader scale. The approach developed in this study can be adapted to other activities provided that equipment and/or bulk material is used to perform those activities, such as rebar installation activity. It can also be used at prefabrication and steel construction sites where equipment utilization is higher.

\section{ACKNOWLEDGMENTS}

This study was funded by The Scientific and Technological Research Council of Turkey (TUBITAK) (Grant \#113M434). Authors would like to thank TUBITAK for their support.

\section{REFERENCES}

Akinci, B., Kiziltas, S., Ergen, E., Karaesmen, I.Z. and Keceli, F. (2006). Modeling and Analyzing the Impact of Technology on Data Capture and Transfer Processes at Construction Sites, J Constr Eng M, ASCE, 32(11), pp. 1148-1157. 
Brilakis I., Park M. and Jog G. (2011), Automated vision tracking of project related entities, Adv Eng Inform, 25, 713-724.

Cheng, T. and Teizer, J. (2013). Real-time resource location data collection and visualization technology for construction safety and activity monitoring applications, Automation in Construction, 34, 3-15.

Costin, A., Pradhananga, N. and Teizer, J. (2012). Leveraging passive RFID technology for construction resource field mobility and status monitoring in a high-rise renovation project, Automation in Construction, 24, 1-15.

El-Omari, S. and Moselhi, O. (2011). Integrating automated data acquisition technologies for progress reporting of construction projects, Automation in Construction, 20, 699705.

Ergen, E., Akinci, B. and Sacks, R. (2007b). Tracking and locating components in a precast storage yard utilizing Radio Frequency Identification Technology and GPS. Automation in Construction, 16(3), 354-367.

Golparvar-Fard, M., Pena-Mora, F. and Savarese, S. (2012). Automated progress monitoring using unordered daily construction photographs and IFC-based building information models, J. Comput. Civ. Eng., 147.

Gong, J. and Caldas, C. (2010). Computer Vision-Based Video Interpretation Model for Automated Productivity Analysis of Construction Operations. J Comput Civil Eng, ASCE, 252-263.

Heydarian, A., Golparvar-Fard, M. and Niebles, J.C. (2012). Automated Visual Recognition of Construction Equipment Actions Using Spatio-Temporal Features and Multiple Binary Support Vector Machines, ASCE, CRC, West Lafayette, IN, USA, 889-898.

Montaser, A. and Moselhi, O. (2012). RFID+ for Tracking Earthmoving Operations, Proc. ASCE Construction Research Congress, West Lafayette, IN, USA, 1011-1020.

Pradhananga, N. and Teizer, J. (2013). Automatic spatio-temporal analysis of construction site equipment operations using GPS data, Automation in Construction, 29, 107-122.

Pradhan, A. and Akinci, B. (2012). Planning-Based Approach for Fusing Data from Multiple Sources for Construction Productivity Monitoring, J Comput Civil Eng, 26(4), 530-540.

Rezazadeh Azar, E., Dickinson, S. and McCabe, B. (2013). Server-customer interaction tracker; a computer vision-based system to estimate dirt loading cycles, J Constr Eng $M$, ASCE, 139(7): 785-794.

Sacks, R., Navon, R., Brodetskaia, I. and Shapira, A. (2005). Feasibility of Automated Monitoring of Lifting Equipment in Support of Project Control, J Constr Eng M, ASCE, 131(5), 604-614.

Shahi, A., Safa, M., Haas, C.T. and West, J.S. (2014). Data Fusion Process Management for Automated Construction Progress Estimation, J Comput Civil Eng, ASCE, 10.1061/(ASCE)CP.1943-5487.0000436, 04014098.

Turkan, Y., Bosche, F., Haas, C.T. and Haas, R. (2012). Toward Automated Earned Value Tracking Using 3D Imaging Tools, J Comput Civil Eng, ASCE, 139(4), 423-433.

Vasenev, A., Pradhananga, N.., Bijleveld, F.R., Ionita, D., Hartmann, T., Teizer, J. and Dorée, A.G., (2014). An information fusion approach for filtering GNSS data sets collected during construction operations, Adv Eng Inform, 28, 297-310.

Weerasinghe, I.P., Ruwanpura J.Y. (2009). Automated Data Acquisition System to Assess Construction Worker Performance, ASCE, CRC, Seattle, Washington, 61-70.

Yang, J., Vela, P.A., Teizer, J., Shi, Z.K. (2012). Vision-Based Tower Crane Tracking for Understanding Construction Activity, J Comput Civil Eng, 28(1), 103-112. 